\title{
A Literature Review on Synthesis and Characterization of enamelled copper wire filled with CNT
}

\author{
D. Edison Selvaraj \\ Department of EEE \\ Panimalar Engineering College \\ Chennai, India
}

\section{Krishnamoorthi \\ M. Raj Kumar}

Department of EEE

Dhanalakshmi Srinivasan

College of Engineering and

Technology Chennai, India

\section{S. Geethadevi}

Department of EEE

Aurora Technological

and Research Institute, Uppal

Hyderabad, India

\author{
G. Dhivya \\ Applied Electronics \\ Dhanalakshmi Srinivasan \\ College of Engineering and \\ Technology Chennai, India
}

\author{
M. Rajmal Joshi \\ Department of EEE \\ Panimalar Engineering College \\ Chennai, India
}

\author{
C. Pugazhendhi Sugumaran \\ Division of High Voltage \\ Engineering \\ College of Engineering \\ Guindy, Chennai, India
}

\section{J. Ganesan}

Department of EEE

Sree Sowdambika College of Engineering, Aruppukottai, India

\section{S. Dinesh Kumar}

Department of EEE

St. Peter's University, Avadi, Chennai, India

\begin{abstract}
This paper discusses about the survey on the various magazines, conference papers and journals for understanding the properties of enamelled copper wires mixed with nano fillers, fundamental methods for synthesis and characterization of carbon nanotubes. From all these papers, it was noted that the research work carried out in an enamelled copper wires filled with nano fillers has shown better results. It was also recorded that the research work was carried mostly with single metal catalysts and very little amount of research work has been carried out on the synthesis of carbon nanotubes using bimetallic catalysts.
\end{abstract}

Keywords: Enamel, Nano fillers, $\mathrm{CNT}, \mathrm{Al}_{2} \mathrm{O}_{3}, \mathrm{TiO}_{2}$

\section{ENAMELLED COPPER WIRES FILLED WITH NANOFILLERS}

P.C.Irwin, Y.Cao, A.Bansal and L.S.Schadler (IEEE 2003) explain the effects of nano-sized fillers on the thermal, mechanical and electrical properties of polymeric systems. Nanofilled polyimide films have shown increased elongation and strength to failure increased scratch hardness and increased thermal conductivity as compared to unfilled materials. Further testing is underway to determine the exact mechanism responsible for the improvement in thermal and mechanical properties [1].

J.Keith Nelson, John C.Fothergill, L.A.Dissado and W.Peasgood (IEEE 2002) examines the effects of nanofillers on space charge accumulation. The fundamental for controlling the dielectric strength of insulating polymers is the cohesive energy density and the associated free volume of the polymer structure are found by change in electric strength and glass transition temperature. Nanometric dimensions affect the dielectric properties. The interaction zone is responsible for the material property modifications [2].

Naoki Hayakawa and Hitoshi Okubo (IEEE 2008) determine the partial discharge characteristics of magnet wires. PD resistant enameled wire filled with inorganic materials has been developed to have longer breakdown lifetimes than those of conventional enameled wires. The breakdown lifetime characteristics of nanocomposite enameled wires increased as a function of nanofiller content. The PD resistance increased with the increasing nanofiller concentration [3]. K.Inuzuka, H.Inano, N.Hayakawa, T.Hirose, M.Hamaguchi and H.Okubo (IEEE 2006) measures the residual life of wires and surface roughness by scanning electron microscope. Nanofillers are useful for improving discharge resistance, matching of coefficient of thermal expansion, thermal conductivity, mechanical reinforcement and abrasion resistance. Increase in the loading weight of nanofiller cause an increase in partial discharge resistance but cause a reduction in mechanical strength which will lead to electrical degradation [4].

Santanu Singha and M.Joy Thomas (IEEE 2008) report an experimental work on the trends of dielectric permittivities and $\tan \delta$ of epoxy nanocomposites with single nanofillers of $\mathrm{Al}_{2} \mathrm{O}_{3}$ and $\mathrm{TiO}_{2}$ at lower filler concentrations $(0.1 \%, 0.5 \%$, $1 \%$ and $5 \%$ ) over a frequency range of $1 \mathrm{MHz}-1 \mathrm{GHz}$. This shows that there is a strong dependence of the filler concentration and nanofiller permittivity at all these frequencies. Tan $\delta$ values in nano composites with $\mathrm{Al}_{2} \mathrm{O}_{3}$ fillers are found to be lower at all filler concentrations when compared with the value for unfilled epoxy [5].

Toshikatsu Tanaka, Masahiro Kozako, Norikazu Fuse and Yoshimichi ohki (IEEE 2005) gives a working hypothesis for 
interaction zones. Several parameters such as chain mobility, chain conformation, crystallinity, degree of the stoichiometry are discussed to formulate the multi-cored model. Triboelectricity was considered for analysis of characteristics. Partial discharge takes zigzag paths to select weak regions consisting of polyamide matrices resulting in strong PD resistance [6].

Hulya Kirkici, Mert Serkan and K. Koppisetty (IEEE 2005) discuss the recent developments in the area of nano-dielectric materials. The effect of nano-scale fillers on electrical, thermal and mechanical properties of polymeric materials was observed. Nano composite materials have higher electrical breakdown strength [7].

M.Q.Nguyen, D.Malec, D.Mary, P.Werynswki, B.Gornicka, L.Therese and Ph.Guillot (IEEE 2009) compare the dielectric and mechanical properties of standard nanoscale -filled and micro scale filled varnishes. The PD occurring between consecutive turns was avoided by using corona-resistant wires and standard enameled wires with a corona-resistant varnish [8].

J. Keith Nelson and John C Fothergill show that the use of nano metric particles results in a substantial change in the behaviour of the composite, which can be traced to the mitigation of internal charge. Interaction zone is responsible for the material property modifications [9].

W. Pfeiffer and M. Paede show that the lifetime of insulation was affected by the environmental conditions. There is just a small dependency of the partial discharge characteristics on temperature and humidity [10].

\section{SYNTHESIS AND CHARACTERIZATION OF CARBON NANOTUBE}

\subsection{Catalyst Preparation}

The Biro L.P, Z.E.Horvath, A.A.Koos, Z.Osvath, Z.Vertesy and L.Tapazto, (2003) has suggested a mechanism for the growth of Carbon Nanotubes. Study on the morphology of the carbon structures grown by CVD showed a significant influence of temperature and the catalyst material on the quality of the carbon nanostructures was observed. The diameter of the nanotubes and the density is adjustable by choosing the corresponding temperature and/or the concentration of the catalyst solution [14].

Resasco. D.E, Alvarez W.E, F.Pompeo, L.Balzano and A.Borgna (2002) put forth a macroscopic characterization method involving surface area measurements and chemical analysis to compare the different nanotube specimens. An increase in the transition metal content of the catalyst yields more carbon nanotubes (up to a metal content of $10.0 \mathrm{wt} \%$ ), but causes a decrease in carbon quality. The best compromise is to use $6.7 \mathrm{wt} \%$ of metal in the catalyst. Co gives superior results with respect to both the quantity and quality of the nanotubes. In the case of $\mathrm{Fe}$, the quality is notably hampered by the formation of $\mathrm{Fe} 3 \mathrm{C}$ particles [28].

Carole E. Baddour and Cedric Briens (2005) have proposed a paper reviewing the various plasma sources currently used in CNT growth, catalyst preparation and growth results. Since the technology is in its early stages, there is a general lack of understanding of growth mechanisms, the role of the plasma itself, and the identity of key species responsible for growth [15].

Li Y.,.Zhang X.B.,Tao X.Y, J.M.Xu, F.Liu and H.J.Geise (2005) has discussed that the decomposition of carbon precursors lead to the formation of a saturated carbon-metal solution. That is the common starting point for most growth models. The next stage of tube growth is carbon precipitation and graphite layer formation. Supersaturated conditions may be reached in different parts of a large flat metal particle independently and a few graphite islands can begin to grow. Further evolution depends on the initial cluster distribution, mobility of the graphite layers, precipitation rate, and possible surface distortions [25].

Jing Kong, Alan M.Cassell and Hongjie Dai (1998) has studied the growth of carbon species over metal catalyst particles under identical conditions. Smaller MWNTs are grown preferentially in narrower diameter distributions when the catalyst particle sizes are smaller. Taken together with the tip-growth and extrusion mechanisms that are well understood for the growth of filamentous carbon fibers, these results bring us closer to achieving structural control over nanotubes synthesized via CVD [22].

\subsection{Characterization of Carbon nanotubes}

From Li T.X., H.G. Zhang, F.J. Wang, Z. Chen and K. Saito (2007) showed that the size of the catalyst nanoparticles is the determining factor for the diameter of the CNT grown on it. Beyond this size correlation, only small nanoparticles are able to catalyze formation of CNT. This can be explained on one hand by the fact that such very small nanoparticles can exhibit peculiar electronic properties due to the unusual high ratio surface atom/bulk atom and on the other hand with a growth mechanism implying the formation of a carbon cap on the nanoparticle surface to reduce its unusual high surface energy. Finally, the crystallographic orientation of the catalyst nanoparticle can be crucial for CNT growth [24].

Liu B.C., B. Yu and M.X. Zhang (2005) proved that vertically well-aligned multi-walled carbon nanotubes (MWNTs) with uniform diameters $(15 \mathrm{~nm})$ were grown on catalytic probes at high yield rates in an inverse diffusion flame (IDF) of a co-flow jet configuration using methane as fuel. Varied parameters investigated included: alloy composition (e.g. $\mathrm{Fe}, \mathrm{Ni} / \mathrm{Cu}, \mathrm{Ni} / \mathrm{Cr} / \mathrm{Fe}$ ), sampling positions within the flame structure, and voltage bias applied to the probe substrate. Spontaneous Raman spectroscopy was utilized to determine the local gas-phase temperature, as well as the concentrations of carbon-based precursor species (e.g. $\mathrm{CO}, \mathrm{C}_{2} \mathrm{H}_{2}$ ) within the flame structure at specific locations of carbon nanotube (CNT) growth during synthesis. The variation of the aforementioned parameters strongly affects CNT formation, diameter, growth rate, and morphology [23].

Matthieu Paillet, Jannik C.Meyer, Thiery Michel, Bruno Chaudret and Ahmed Zahab (2006) discussed the experimental and theoretical facts relevant for the catalytic growth of multiwall nanotubes by chemical vapor deposition, taking them as a basis for a more macroscopic, thermo dynamical model. It was found that the growth is mainly driven by a concentration gradient as opposed to a thermal 
gradient, while the process temperature plays a key role in terms of activating diffusion [27].

Mariano Escobar, M. Sergio Moreno, Roberto J. Candal, M. Claudia Marchi, Alvaro Caso, Pablo I. Polosecki, Gerardo H. Rubiolo and Silvia Goyanes (2007) researched the rate of deposition of Carbon Nanotubes, their purity and wall thickness employing different Chemical Vapour Deposition processes. It was found that product purity and wall thickness was depended on process temperature, carbon precursor, concentration of catalyst during deposition [26].

Segura R., M.Flores, S.Hevia and P.Haberle (2007) investigated the Iron/molybdenum/magnesium mixed oxide prepared by a sol-gel method showing its high efficiency for synthesis of MWNTs through catalytic decomposition of Methane using Chemical Vapor Deposition method at $1000^{\circ} \mathrm{C}$. The weight production of the as-grown MWNTs can reach as high as 30 times of the catalyst in 30 min growth. Upon SEM and TEM observations, the product is found to be compacted bundles of MWNTs. Microstructure of the tubes was characterized by Transmission Electron Microscopy and Raman Spectroscopy. Thermal gravimetric analysis examination showed that the content of MWNT is high. Using this high-efficient catalyst, the cost of producing carbon nanotubes can be greatly reduced [29].

Yu G.J., Gong J.L, S.X. He, J.Q. Cao and Z.Y. Zhu (2006) demonstrated that uniform iron-molybdenum nanoparticles can be prepared by thermal decomposition of metal carbonyl complexes using a mixture of long-chain carboxylic acid and long-chain amine as protective agents. The sizes of the nanoparticles can be systematically varied from 3 to $14 \mathrm{~nm}$ by changing the experimental conditions. High-resolution TEM images and EDX data show that the prepared nanoparticles are highly crystalline iron nanoparticles containing 4\% molybdenum. The effects of the concentration, reaction time, the ratio of metal carbonyl complexes versus protective agents, and the ratio of acid/amine of the protective agents on the sizes of the produced nanoparticles were systematically studied. The prepared nanoparticles were used as catalysts for single-walled carbon nanotube growth and the results indicate that there is an upper limit for the size of the catalyst particles to nucleate single walled carbon nanotubes [32].

\subsection{Synthesis of carbon nanotubes by CVD}

Carbon Guo. P.S. Z. Sun, Y.W. Chen and Z.H. Zheng (2006) has conducted a research using nickel foil as both substrate and catalyst, reported a simple, cheap and easily controllable thermal chemical vapor deposition (CVD) for mass synthesis of carbon nanotubes (MWNTs). Grams of CNTs with high purity and good uniformity have been obtained on the nickel foil at $550{ }^{\circ} \mathrm{C}$ in a gas mixture of $\mathrm{C}_{2} \mathrm{H}_{2}$ and $\mathrm{H}_{2}$. The asprepared CNTs were screen-printed on $\mathrm{Ag}$ electrodes patterned on glass to form field emission cathodes. The cathodes exhibit excellent field emission properties, with a turn-on field of $1.0 \mathrm{~V} / \mu \mathrm{m}$, the emission current density of 1 $\mathrm{mA} / \mathrm{cm}^{2}$ at $2.5 \mathrm{~V} / \mu \mathrm{m}$, and uniform emission luminescence. This CVD method shows great promise in large-scale production of raw materials of CNTs for application of field emission display [19].

Andrews R., D.Jacques, E.C.Dickey and D.Qian (2003) showed that Chemical vapor deposition (CVD) is the most promising synthesis route for economically producing large quantities of carbon nanotubes. We have developed a low-cost
CVD process for the continuous production of aligned multiwall carbon nanotubes (MWNTs). The effects of reactor temperature, reaction time, and carbon partial pressure on the yield, purity, and size of the MWNTs produced were reported. A simple method for purifying and healing structural defects in the nanotubes is described. The dispersion of nanotubes in polymer matrices has been investigated as a means of deriving new and advanced engineering materials. These composite materials have been formed into fibers and thin films and their mechanical and electrical properties determined [13].

Sing B.K, Sung-Wook Cho, K.S.Bartwal, Nguyen Duc Hoa and Hojin Ryu (2007) proved that Multiwalled carbon nanotubes (MWNTs) can be synthesized by chemical vapor deposition technique using $\mathrm{MgO}$ supported bimetallic $\mathrm{Fe}-\mathrm{Mo}$ catalyst. The role of Mo on the quality of as-synthesized CNTs and their application in field emission has been investigated. The field emission properties of the device fabricated from the CNTs synthesized with $\mathrm{Fe}-\mathrm{Mo}$ catalyst was found to be better than the similar device prepared with CNTs synthesized with Fe catalyst alone [30].

Tao X.Y. a,b, X.B. Zhang a,b,., F.Y. Sun c, J.P. Cheng a,b, F. Liu a and Z.Q. Luo (2007) conducted an experimental study to investigate the synthesis of multi-walled carbon nanotubes (CNTs) in counter flow methane-air diffusion flames, with emphasis on effects of catalyst, temperature, and the air-side strain rate of the CNT growth. The counter flow flame was formed by fuel $(\mathrm{CH} 4$ or $\mathrm{CH} 4+\mathrm{N} 2)$ and air streams impinging on each other. Two types of substrates were used to deposit CNTs. Ni-alloy $(60 \% \mathrm{Ni}+26 \% \mathrm{Cr}+14 \% \mathrm{Fe})$ wire substrates synthesized curved and entangled CNTs, which have both straight and bamboo-like structures; Si-substrates with porous anodic aluminum oxide (AAO) nanotemplates synthesized well-aligned, self-assembled CNTs thermocouple with a $0.3 \mathrm{~mm}$ bead junction. It was found that temperature could affect not only the success of CNTs synthesis, but also the morphology of synthesized CNTs. It was also found, against previous general belief, that there was a common temperature region $(1023-1073 \mathrm{~K})$ in chemical vapor deposition (CVD) where CNTs could be produced [31].

\section{CONCLUSION}

From the literature survey it was observed that the research work carried out in an enamelled copper wire filled with nano fillers has shown better results. It was also noted that the research work was carried mostly with single metal catalysts and very little amount of research work has been carried out on the synthesis of carbon nano tubes using bimetallic catalysts. Hence it was decided to take up research on synthesis of carbon nanotubes using bimetallic catalyst. nanotubes [32].

\section{REFERENCES}

[1] P.C.Irwin, Y.Cao, A.Bansal and L.S.Schadler, "Thermal and mechanical properties of polyimide nanocomposites", IEEE 2003

[2] J.Keith Nelson, John C.Fothergill,L.A.Dissado and W.Peasgood, "Towards an understanding of nanometric dielectrics", IEEE 2002 
[3] Naoki Hayakawa and Hitoshi Okubo, "lifetime characteristics of nanocomposite enameled wire under surge voltage application", IEEE 2008.

[4] K.Inuzuka, H.Inano, N.Hayakawa, T.Hirose, M.Hamaguchi and H.Okubo , "Partial discharge characteristics of nanocomposite enameled wire for inverter fed motor", IEEEE 2006.

[5] Santanu Singha and M.Joy Thomas, "Permittivity and tan delta characteristics of epoxy nanocomposites in the frequency range of $1 \mathrm{mhz}-1$ ghz", IEEE 2008.

[6] Toshikatsu Tanaka, Masahiro Kozako, Norikazu Fuse and Yoshimichi ohki, "Proposal of a multi-cored model for polymer nanocomposite dielectrics", IEEE 2005.

[7] Hulya Kirkici, Mert Serkan and K.Koppisetty , "Nanodielectric materials in electrical insulation application", IEEE 2005.

[8] M.Q.Nguyen ,D.Malec ,D.Mary ,P.Werynswki ,B.Gornicka, L.Therese and Ph.Guillot, "Investigations on dielectric properties of enameled wires with nanofilled varnish for rotating machines fed by inverters", IEEE 2009.

[9] J. Keith Nelson and John C Fothergill, "Internal charge behaviour of nanocomposites", Institute of Physics Publishing, 2004.

[10] W. Pfeiffer and M. Paede, "About the influence of the environmental conditions on the partial discharge characteristics of enameled wire at high frequency voltage".

[11] IEC 60851, Methods of test for winding wires, 1994.

[12] IEC 61251: Electrical insulating materials - A.C. voltage endurance evaluation. IEC, Geneva, 1993.

[13] Andrews R., D.Jacques, E.C.Dickey and D.Qian,(2003) "Synthesis and growth mechanism of multiwalled carbon nanotubes", Center for Applied Energy Research, University of Kentucky.

[14] Biro L.P., Z.E.Horvath, A.A.Koos, Z.Osvath, Z.Vertesy and L.Tapazto, (2003) "Direct synthesis of multi-walled and single walled carbon nanotubes by spraypyrolysis", Journal of Optoelectronics and advanced materials, Vol.5, issue 3, pp 661- 666.

[15] Carole E. Baddour and Cedric Briens (2005) "Carbon Nanotube Synthesis: A Review", International Journal of Chemical Reactor Engineering, Vol 3, Review R3

[16] Couteau E., J.W. Seo, L Thien-Nga, Cs. Mik, R.Gaal, L.Forro, (2003) "CVD synthesis of high-purity multiwalled carbon nanotubes using $\mathrm{CaCO} 3$ catalyst support for large-scale production" Chemical Physics Letters 378, pp 9-17.

[17] Engel-Herbert R. a, H. Pforte b, T. Hesjedal, (2007) “CVD synthesis and purification of single-walled carbon nanotubes using silica-supported metal catalyst" Materials Letters 61, pp 2589-2593.
[18] Giuseppe Gulino, Ricardo Vieira, Julien Amadou, Patrick Nguyen, Marc J. Ledoux, Signorino Galvagno, Gabriele Centi, Cuong Pham- Huu,(2005) "C2H6 as an active carbon source for a large scale synthesis of carbon nanotubes by chemical vapour deposition" Applied Catalysis A:General 279, pp 89-97.

[19] Guo. P.S. Z. Sun, Y.W. Chen, Z.H. Zheng (2006) “A novel approach to mass synthesis of raw CNTs for printed field emission cathodes by chemical vapour deposition” Materials Letter, Vol.60, pp 966-969.

[20] Hiroshi Kinoshita ., Ippei Ippei, Hirokazu Sakai, Nobuo Ohmae,(2007) "Synthesis and mechanical properties of carbon nanotube/diamond-like carbon composite films", Diamond \& Related Materials 16, pp 1940-1944.

[21] Jipeng Cheng, Xiaobin Zhang, Zhiqiang Luo, Fu Liu, Ying Ye, Wanzhong Yin, Wei Liu, Yuexin Han, (2006) "Carbon nanotube synthesis and parametric study using $\mathrm{CaCO}_{3}$ nanocrystals as catalyst support by CVD" Materials Chemistry and Physics 95, pp 5-11

[22] Jing Kong, Alan M.Cassell, Hongjie Dai,(1998) "Chemical Vapour Deposition of methane for single walled carbon nanotubes", Chemical Physics Letters 292,pp $567-574$.

[23] Liu B.C., B. Yu, M.X. Zhang , (2005)“"Catalytic CVD synthesis of double-walled carbon nanotubes with a narrow distribution of diameters over $\mathrm{Fe}-\mathrm{Co} / \mathrm{MgO}$ catalyst" Chemical Physics Letters 407, pp 232-235.

[24] Li T.X., H.G. Zhang, F.J. Wang, Z. Chen , K. Saito, (2007) "Synthesis of carbon nanotubes on Ni-alloy and Si-substrates using counter flow methane air diffusion flames", Proceedings of the Combustion Institute 31, pp 1849-1856

[25] Li Y.,.Zhang X.B,.Tao X.Y, J.M.Xu, F.Liu and H.J.Geise, (2005) "Single phase $\mathrm{MgMoO} 4$ as catalyst for the synthesis of bundled multi-wall carbon nanotubes by CVD”, Journal of Carbon, 43, pp 1325 - 1328.

[26] Mariano Escobar, M. Sergio Moreno, Roberto J. Candal, M. Claudia Marchi, Alvaro Caso, Pablo I. Polosecki, Gerardo H. Rubiolo, Silvia Goyanes,(2007) "Synthesis of carbon nanotubes by CVD: Effect of acetylene pressure on nanotubes characteristics" Applied Surface Science 254, pp $251-256$

[27] Matthieu Paillet, Jannik C.Meyer, Thiery Michel, Bruno Chaudret and Ahmed Zahab, (2006) "Selective growth of large chiral angle single walled carbon nanotubes", Diamond \& Related Materials, 15, pp 1019 - 1022

[28] Resasco. D.E., Alvarez W.E., F.Pompeo, L.Balzano and A.Borgna, (2002) "A scalable process for production of single-walled carbon nanotubes by catalytic disproportionation of $\mathrm{CO}$ on a solid catalyst", Journal of Nanoparticle Research, Vol 4, pp 131-136.

[29] Segura R., M.Flores, S.Hevia, P.Haberle, (2007) "Synthesis, characterization and spectroscopy of carbon based nanoscale materials", Microelectronics Journal Article in press. 
[30] Sing B.K, Sung-Wook Cho, K.S.Bartwal, Nguyen Duc Hoa,Hojin Ryu(2007) "Synthesis of MWNTs using FeMo bimetallic catalyst by CVD method for field emission application", Solid State Communications 144, pp 498-502.

[31] Tao X.Y. a,b, X.B. Zhang a,b,., F.Y. Sun c, J.P. Cheng a,b, F. Liu a, Z.Q. Luo,(2007) "Large-scale CVD synthesis of nitrogen-doped multi-walled carbon nanotubes with controllable nitrogen content on a CoxMg1-xMoO4 catalyst", Diamond \& Related Materials 16, pp 425-430

[32] Yu G.J., Gong J.L, S.X. He, J.Q. Cao, Z.Y. Zhu, (2006) "Efficient synthesis of carbon nanotubes over rare earth zeolites by thermal chemical vapor deposition at low temperature" Diamond \& Related Materials 15, pp 1261 1265

[33] M S Naidu and V Kamaraju, "High Voltage Engineering" Solid dielectrics used in practice pp $106-122$.

[34] Dieter Kind and Hermann Kamer, "High Voltage Insulation Technology" 1985.

[35] E. Kuffel, W.S. Zaengl and J. Kuffel, "High Voltage Engineering Fundamentals" Partial discharge measurements pp $421-456$.

[36] Partial discharge measurements, IEC 270, 1981.

[37] IEC standard 60270: 1999 Partial discharge measurements.

[38] B. Tareev "Physics of Dielectric Materials" Tests for thermal ageing pp $234-235$.

[39] M. Arumugam "Material Science" Scanning Electron Microscope pp 423. 